\title{
Copagamentos no Sistema Público Brasileiro: anomalia ou tendência?
}

\author{
Joint payment in the Brazilian Public Health System: anomaly or tendency?
}

\author{
Maria de Fatima Siliansky de Andreazzi* \\ Marco Antonio Ratzsch de Andreazzi** \\ Luciléia de Souza Baptista** \\ Eduardo Scarlatelli Pimenta ${ }^{* * *}$
}

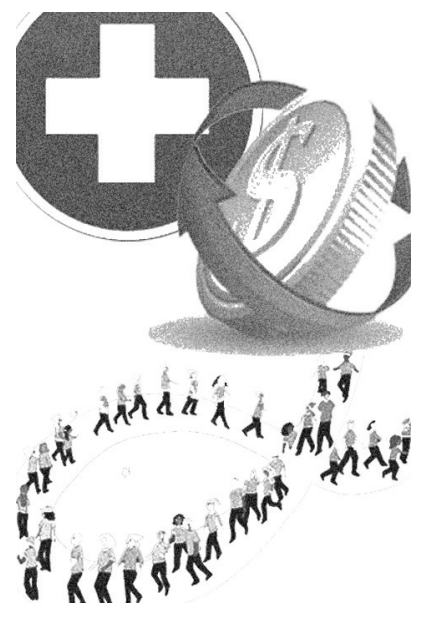

Resumo: O copagamento como complemento ao financiamento de unidades públicas de saúde é uma recomendação específica do Banco Mundial para reformar sistemas de saúde e tem sido amplamente utilizado no contexto internacional. O Brasil é uma exceção. O objetivo do trabalho foi analisar a situação do copagamento no Sistema Único de Saúde diante da constatação de sua ocorrência em dois municípios de uma microrregião de Minas Gerais. A questão principal a ser respondida foi: trata-se de um caso anômalo, isolado, ou uma prática não privilegiada pelas análises da implementação da política de saúde no Brasil na atualidade, uma tendência a ser monitorada?

Palavras-chave: Serviços de saúde. Financiamento em saúde. Reformas dos serviços de saúde. Economia da saúde. Política de saúde: Brasil.

\begin{abstract}
Joint payment as a complement to finance public health unities is a specific recommendation by the World Bank in order to rearrange health systems, and it has been widely used throughout

* Doutora em Saúde Coletiva Instituto de Medicina Social da UERJ. Professora-adjunta, Departamento de Medicina Preventiva da UFRJ — Rio de Janeiro/RJ, Brasil. E-mail: siliansky@iesc.ufrj.br.

** Doutor em Saúde Coletiva pela FIOCRUZ — Rio de Janeiro/RJ, Brasil. Pesquisador da Coordenação de População e Indicadores Sociais do IBGE.

*** Assistente social, Prefeitura Municipal de Niterói/RJ, Brasil.

**** Estudante de Medicina da Universidade Estácio de Sá, coordenador do Socorro Popular do Rio de Janeiro/RJ, Brasil.
\end{abstract}


the world. Brazil is an exception. The aim of the article is to analyze the situation of joint payment in Sistema Único de Saúde - SUS - (Unique Health System) in two cities of a micro-region in Minas Gerais State. The main question to be answered was if we were facing an anomalous isolated case or if it was a practice non-privileged by the analyses of implementation of public health currently in Brazil, a tendency to be monitored.

Keywords: Health services. Health financing. Rearrangements in health services. Health economy. Health policy: Brazil.

\section{Introdução}

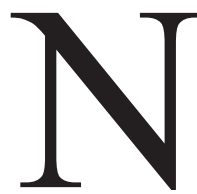

ão é novidade para nenhum estudioso das políticas de saúde que a descentralização se constitui um dos pilares das recomendações que os organismos financeiros internacionais fazem para remodelar o setor saúde, particularmente em países não centrais do capitalismo. Trechos do emblemático documento do Banco Mundial de (1989) ilustram esse ponto:

Descentralização do planejamento, orçamentação e compras para os serviços governamentais, particularmente aqueles de trazem benefícios privados pelos quais se cobra dos usuários. Ao determinar as políticas e programas nacionais, emprego de incentivos de mercado onde seja possível a fim de motivar o pessoal e alocar melhor os recursos. Permitir que a cobrança e o uso das tarifas se faça o mais próximo possível do ponto de prestação dos serviços, porque isto melhorará tanto a cobrança das tarifas como a eficiência dos serviços...Nos países onde existe escassez de recursos gerenciais, onde a comunicação é difícil, a locomoção lenta e muita gente se encontra isolada, a descentralização dos serviços governamentais deve considerar-se como uma forma de melhorar a eficiência. (Banco Mundial, 1989, p. 153-154; tradução livre)

É polêmico, entretanto, que a reforma do sistema de saúde no Brasil, consolidada nos princípios da Constituição de 1988 pela universalidade (CF, art. 196) e integralidade (CF, art. 198, § II) e na Lei Orgânica de 1990 pela descentralização e pela gratuidade (Lei n. 8.080/90, art. 43), tenha permitido a implementação da agenda dos organismos internacionais no setor. Seus determinantes, relacionados ao processo de ampliação do protesto popular que 
conforma a conjuntura do final do período do regime militar, foram opostos a esse ideário. Em pontos concretos, entretanto, a reforma coincide com as proposições daqueles organismos financeiros. Esse é o caso específico da descentralização no país, não associada legalmente aos copagamentos em serviços públicos de saúde nos projetos que embasaram a reforma, a descentralização tinha por objetivo adequar melhor as ações públicas às necessidades diversas de um grande país heterogêneo e permitir um controle social mais próximo da execução das ações. Isso sem subtrair a importância do Estado nacional no financiamento e na coordenação da política de saúde, ao contrário do receituário neoliberal. Precisa-se que, de per si, o copagamento não se constitua numa prática unicamente relacionada a uma política de cunho neoliberal, dado sua existência residual em sistemas de saúde baseados na universalidade de direitos para alguns bens e serviços, como, por exemplo, medicamentos, e distribuído de forma progressiva entre a população, isentando os mais pobres. Entretanto, é adotada, fundamentalmente, pelo neoliberalismo, para o conjunto da população.

Outro aspecto dessas políticas se refere à reforma dos mecanismos de gestão do Estado rumo à separação do financiamento da prestação de serviços de saúde (Almeida, 2002) e a terceirização da gestão dos estabelecimentos públicos, que se constitui em elemento que viabiliza que a descentralização possa ser acompanhada da diversificação de fontes de financiamento para as unidades públicas de saúde. No país, a transformação das unidades de saúde da administração direta do Estado em entes privados sem finalidades lucrativas na forma de organizações sociais, fundações de direito privado e similares tem sofrido uma trajetória crescente, principalmente a partir do impulso gerado pelo governo federal à reforma do Estado em meados dos anos 1990 (Brasil, Maré, 1995), não sem resistência de setores organizados da população. Críticas se dirigem às perdas de direitos trabalhistas dos profissionais de saúde, mas também às possibilidades de práticas privadas nesses estabelecimentos, ferindo o princípio da equidade constitutivo do sistema público de saúde.

Mas essas práticas estavam claramente apontadas nas recomendações que o Banco Mundial fez, especificamente para o Brasil, nos anos 1990 (Banco Mundial, 1991 e 1995). Constam, nesses documentos, o estabelecimento de um pacote de benefícios de saúde-padrão e a limitação do acesso a serviços de 
atenção terciários, ambos uma recomendação constante no relatório geral do Banco de 1993 (Banco Mundial, 1993). E, ainda, o incentivo à concorrência na prestação de serviços ambulatoriais e hospitalares, envolvendo indistintamente os setores públicos e privados, bem como a adoção de formas de copagamentos. A última recomendação aparece tanto no trabalho do Banco Mundial de 1991 como de 1995. Nesse último ano, o texto assim apresentava a questão: "Experimentar mecanismos de copagamento, com base nos resultados do levantamento sobre demanda, e em experiências em estados e municípios, cobrando apenas de pacientes com renda acima de certo valor, para a proteção dos mais pobres" (Banco Mundial 1995, p. xxiii).

No Brasil, entretanto, não é tradição a cobrança legalizada em unidades públicas de saúde, ao contrário de outros países centrais e não centrais, inclusive de grande parte das Américas (Bjorkman, 2009).

No extinto Instituto de Assistência Médica da Previdência Social, nas décadas de 1960 e 1970, ela esteve associada à possibilidade de melhorias em acomodações hospitalares nos hospitais privados contratados pelo Instituto, assim como nos honorários profissionais, para usuários que assim o desejassem. Essa prática foi abolida em 1981 (Vianna, Piola e Ocké-Reis, 1998).

Após a reforma constitucional de 1988, análises sobre o tema do copagamento no sistema público brasileiro são bastante escassas. Destaca-se o trabalho de Vianna, Piola e Ocké-Reis (1998), fruto de pesquisa sobre o tema. Para esses autores, essa prática seria bastante difundida nos anos 1990, tanto para honorários profissionais quanto para serviços hospitalares "sem aparente reação objetiva das autoridades do setor e dos órgãos profissionais responsáveis pela vigilância do comportamento ético de seus filiados...” (1998, p. 24). Em pesquisa de campo realizada em dois municípios do Rio Grande do Sul, constataram que recursos municipais eram usados para complementar a tabela de referência e pagamentos do SUS. Em um deles, a cobrança por fora (copagamento) no único hospital que atende ao SUS, de caráter filantrópico, para atendimentos ambulatoriais eletivos, teria sido aprovada pelo Conselho Municipal de Saúde. A receita arrecadada seria repassada para o Fundo Municipal de Saúde, numa prática que afrontaria a legislação federal quanto à gratuidade. No outro caso, que ocorria em um hospital filantrópico e um lucrativo contratado pelo SUS, a população teria demandado providên- 
cias à prefeitura para coibir a prática, o que teria sido feito por meio de reembolso aos usuários e cobrança aos hospitais e médicos dos copagamentos registrados da delegacia de polícia. De modo geral, os autores sugeriram a ocorrência de uma prática generalizada entre hospitais contratados pelo SUS, no início da década de 1990, a partir de constatação do presidente da Federação Brasileira de Hospitais.

Além disso, nesse mesmo trabalho de Vianna, Piola e Ocké-Reis (1998) eram referidas denúncias, nos anos 1990, por parte da Associação de Servidores, de práticas de privilegiamento do acesso de pacientes pagantes vis-à-vis os gratuitos no âmbito do Hospital de Clínicas de São Paulo (universitário público).

Vale lembrar, portanto, que não sendo legal, a cobrança a usuário do SUS consta entre as infrações consideradas pelo Departamento Nacional de Auditoria do SUS (Denasus) do Ministério da Saúde (2005), passível de ressarcimento por parte do prestador e encaminhamento ao Ministério Público:

Uma vez devidamente comprovada a cobrança por prestador de serviço a usuário do SUS, a título de complementaridade, fazer recomendação ao gestor para providências junto ao prestador, visando à restituição em dobro dos valores cobrados, fundamentada no art. 197 da Constituição Federal de 1988; art. 33, § $4^{\circ}$, arts. 43 e 52 da Lei n. 8.080/1990 (Lei Orgânica da Saúde), combinados com o parágrafo único do art. 42 da Lei n. 8.078/1990 (Código de Proteção e Defesa do Consumidor) e com a PT MS/SAS n. 113/97. Neste caso, comunicar o fato ao Ministério Público, para a adoção das medidas de sua competência.

A comprovação deve ser buscada ouvindo-se o usuário, se possível, com o objetivo de identificar o valor pago e a quem foi pago (médico, hospital, funcionário do hospital ou do médico, setor do hospital). (Brasil, Ministério da Saúde, 2005, p. 40)

\section{Objetivo e metodologia}

O objetivo do trabalho foi analisar a situação do copagamento no SUS diante da constatação de sua ocorrência em dois municípios de uma microrregião do estado de Minas Gerais. A questão principal a ser respondida foi: 
trata-se de um caso anômalo ou isolado, uma prática não privilegiada pelas análises da implementação da política de saúde no Brasil na atualidade ou uma tendência a ser monitorada em face da sua disseminação global como uma recomendação expressa por importantes organismos internacionais financeiros e de cooperação?

Trata-se de um estudo exploratório no qual, inicialmente, é realizada uma pesquisa bibliográfica sobre o copagamento no setor público de saúde no Brasil a partir dos anos 1990. Observa-se a magnitude do fato na Pesquisa Nacional por Amostra de Domicílios (PNAD) — Suplemento Saúde de 1993, realizada pelo órgão oficial de estatísticas brasileiro. Em seguida, são descritos os casos estudados. Finalmente, algumas tendências são delineadas e considerações realizadas à luz da conjuntura político-administrativa da saúde no país. É importante considerar que o copagamento foi descoberto por intermédio de um trabalho que tinha como objetivo analisar determinantes socioeconômicos de saúde de população rural do semiárido, que suscitou o interesse tanto no balanço do problema no Brasil na atualidade como na própria divulgação, dada a sua pouca visibilidade no debate acadêmico atual.

A pesquisa bibliográfica, datada do mês de agosto de 2009, realizada nas bases de dados "Scielo" e "Lilacs" com as palavras-chave "copagamento", "saúde" e "Brasil", selecionou apenas o trabalho já identificado previamente (Vianna, Piola e Ocké-Reis, 1998). Com a ferramenta de busca Google Scholar, retirando-se o setor privado da análise, foram encontrados 34 trabalhos, dos quais, além do já identificado anteriormente, somente um pode ser selecionado (Melo et al., 2008). Com as palavras-chave "cobrança", "saúde" e "Brasil" nenhum artigo foi encontrado no Scielo e na base Lilacs, dez artigos foram listados, onde apenas um se encaixava no perfil definido, já identificado anteriormente. No Google Scholar, os descritores "cobrança", "usuário", "SUS", "Denasus" resultaram em dezoito documentos, selecionando-se mais dois estudos, um deles de caso, que foram aqui incorporados (Ribeiro, 2002 e Melo, 2007). Outros estudos de caso (Espindola, 2004 e Melo, 2005) foram incorporados a partir das referências bibliográficas dos textos inicialmente selecionados.

No caso do Suplemento da Saúde da PNAD de 2003, foi utilizada a Base Multidimensional de Dados do órgão, a partir das variáveis: "Principal atendimento cobertura SUS" associado com "Principal atendimento cobertura pagamento". 
Os levantamentos de campo que resultaram no estudo de caso aqui relatado foram realizados em julho de 2009 em localidades rurais de dois municípios do norte de Minas Gerais. O trabalho foi solicitado pelas entidades representativas dos camponeses ao Socorro Popular do Rio de Janeiro, organização de solidariedade e assessoria a lutas populares, da qual os autores são integrantes e/ou apoiadores. A metodologia, de cunho participativo, foi discutida e aprovada em assembleia geral, e os resultados devolvidos prontamente para a população. O consentimento dos indivíduos em participar da entrevista foi previamente obtido, não havendo nenhuma negativa. Para a descrição e análise dos resultados foram consideradas variáveis demográficas e sociais dos respectivos municípios, assim como breve caracterização administrativa do sistema de saúde a partir de dados secundários constantes da base de dados eletrônica do SUS (Datasus), entrevistas e observação participante. Assim, foram realizadas entrevistas semiestruturadas a partir de um questionário nos domicílios e dois grupos focais com lideranças e moradores de duas comunidades com a participação média de cinquenta pessoas com o tema "situação de saúde e de atenção à saúde". A partir dos relatos verificados, foi realizada uma observação participante em uma audiência que a entidade representativa de uma das comunidades solicitou ao secretário municipal de Saúde de um desses municípios. Foram aplicados quarenta questionários. Para os grupos focais, foram designados relatores que anotaram os principais temas discutidos em um caderno de campo. A observação participante foi filmada, e os principais temas abordados posteriormente anotados no caderno de campo. Os depoimentos, tanto dos moradores quanto do secretário de Saúde, foram categorizados e classificados de acordo com grandes temas a partir de metodologia de análise de conteúdo (Bardin, 1997). Tal proposta metodológica está ancorada em nas chamadas metodologias rápidas de avaliação - RAP (Kumar, 1993).

\section{Resultados}

A prática do copagamento no setor público de saúde, no Brasil, afora o trabalho de Vianna, Piola e Ocké-Reis (1998) está bem pouco mapeada acadêmica e tecnicamente. 
Melo (2005) descreve a cobrança por consultas médicas nos hospitais conveniados do SUS, em cidade de mais de 400 mil habitantes, do interior do estado do Rio de Janeiro, já detectada em 1996, a partir de fonte do próprio Conselho Municipal de Saúde.

Melo et al. (2008), a partir de análise qualitativa de entrevistas e grupos focais com vários sujeitos sociais em três municípios do estado de Mato Grosso, em data não referida, visando a avaliação da implantação do Programa Saúde da Família, investigaram especificamente a existência de copagamento para consultas e não encontraram a prática em nenhum município.

Trabalhos de cunho oficial, entretanto, sugerem que a cobrança não é infrequente. Assim, Ribeiro (2002), a partir das cartas de usuários recebidas pelo Ministério da Saúde, refere que, de 1999, quando foi implantado, até maio de 2002 ,

953 pessoas foram ressarcidas de valores cobrados indevidamente por hospitais e/ou profissionais; em relação aos hospitais ocorreram 17 exclusões, 45 multas, 27 suspensões e 532 advertências; em relação aos profissionais médicos, 3 foram excluídos, 6 suspensos e 66 foram advertidos; além disso, foram aplicadas 53 advertências públicas e determinadas 635 emissões de ordens de recebimento (OR-restituições ao SUS). (p. 9-10).

O ressarcimento ao usuário, entretanto, não está previsto no Manual de Glosas do Denasus (Brasil, Ministério da Saúde, 2005). Melo (2007, p. 185) contesta a norma, afirmando que "esse ressarcimento ao Fundo Nacional de Saúde deveria ser repassado ao usuário, que disponibilizou o dinheiro. O ressarcimento é reconhecido somente como direito dos cofres públicos".

Um estudo de caso de oito municípios da Regional de Saúde de Campo Grande - MS (Espindola, 2004) objetivou analisar os principais motivos de denúncias de usuários por meio de cartas enviadas para a Ouvidora do SUS do Ministério da Saúde entre 2001 e 2003, num total de treze denúncias. Os municípios possuíam entre 3 mil e 18 mil habitantes e não envolviam a capital: "As denúncias concentraram-se em dois motivos: cobrança pelo atendimento, ou seja, cobrança indevida que representou $77 \%$ do total, e a falsificação de internação, com 23\%" (p. 42). 
Na PNAD 2003, a associação de pagamento e cobertura SUS não se revelou de monta, com menos de $1 \%$ dos atendimentos cobertos pelo SUS (principal atendimento) pagos simultaneamente pelo usuário, com maiores proporções em alguns estados da Região Norte.

Os municípios - casos estudados situam-se no norte de Minas, microrregião de Montes Claros. A estimativa da população de X, em 2009, foi de 19.769 habitantes (Brasil, Ministério da Saúde, 2009) e de Y, 26.985 habitantes. $\mathrm{X}$ tem sua economia baseada na agricultura e pecuária de corte e no momento da pesquisa era governado pelo PT. ${ }^{1} \mathrm{Y}$ é um município mais antigo, de perfil produtivo parecido, governado no mesmo momento pelo PSDB. Ambos estão entre os municípios de menor PIB per capita do estado de Minas Gerais.

Os dados da rede assistencial apresentados a seguir foram de dezembro de 2007. X tem uma rede de atenção à saúde pública ambulatorial, e todos os leitos de seu hospital privado são cadastrados pelo SUS (27 leitos, com uma taxa de cobertura de 1,3 leito por mil habitantes). Já Y tem uma rede ambulatorial maior e um hospital público com 37 leitos, inclusive cirúrgicos (1,4 leito por mil habitantes). X possui quatro equipamentos de raio $\mathrm{X}$, ultrassom e equipamento odontológico completos, realizando consultas e procedimentos especializados e exames de patologia clínica. Já Y, além da oferta menor de raio X (apenas um aparelho), não possui ultrassom. Todos os serviços existentes, equipamentos e recursos humanos eram cadastrados como atendendo somente ao SUS em 2007 em ambos os municípios. Como resultado da baixa oferta de leitos, 30\% das internações dos munícipes de X são fora do município, com uma cobertura ainda baixa, no total de 7,3 internações por cem habitantes em 2007. Y interna a maior parte dos seus munícipes, apresentando em 2007 uma taxa de 6,7 internações por cem habitantes por local de residência e 6,8 por local de internação. Em X, a população coberta pelo Programa de Saúde da Família (PSF) passa de 50,4\% em 2005 para 98\% em 2008 e em Y de 49,3\% para $101 \%$ no mesmo período, taxa essa que indica, possivelmente, estimativas inacuradas em relação à população residente. A despesa total com saúde em X, em 2007 foi de R\$155,69 per capita (US 80,83), sendo 58,6\% oriunda de

1. Ver Cidades@, IBGE. Disponível em: <http:www.ibge.gov.br>. Acesso em: 20 ago. 2009. 
transferências do SUS. A partir de 2005, o município tem aplicado o limite da Emenda Constitucional n. 29/2000 em saúde (15\% dos recursos próprios). Y apresentou o gasto total de R $\$ 187,42$ (US 97,30) em 2007, sendo 58,5\% oriundos do SUS, e também se mantém em torno de $15 \%$ da despesa de recursos próprios aplicada em saúde.

A microrregião de Montes Claros apresentou em 2008, segundo dados do Datasus, 101.542 internações, 16,75 por cem habitantes. A sua maior parte foi em hospitais filantrópicos isentos de tributos e contribuições sociais; apenas 5\% em privados contratados. Todos os municípios da microrregião possuem atenção básica e média complexidade. Apenas dois (especialmente o município-sede) possuem alta complexidade, onde somente $9 \%$ dos procedimentos se deram na esfera privada, com ênfase na filantrópica. Entretanto, os procedimentos de média complexidade, $47,7 \%$ foram realizados na rede privada, metade dos quais em estabelecimentos privados lucrativos. Observa-se, portanto, uma especialização da rede privada de atenção à saúde.

O estudo de campo foi realizado em duas localidades rurais contíguas, áreas camponesas cujo movimento de luta pela terra era ligado à Liga dos Camponeses Pobres do Norte de Minas Gerais, uma pertencendo a X e outra a Y. Em X, foi realizado um levantamento das condições de saúde e atenção à saúde por meio de entrevistas semiestruturadas em vinte domicílios que somavam 120 pessoas. Isso representou metade dos domicílios da localidade, sendo que muitos estavam fechados. Eram formados de pequenos proprietários rurais, com produção agrícola e pecuária basicamente de subsistência, e economia monetária pouco desenvolvida. Em Y, o levantamento abrangeu catorze domicílios, faltando apenas um para completar a totalidade, e eram formados por antigos posseiros, hoje proprietários. Entendendo a utilização de serviços de saúde como resultante da interação entre características do indivíduo e dos serviços (organização e política) (Travassos e Martins, 2004), viu-se que os habitantes da localidade do município Y referiram uma situação de atendimento à saúde mais facilitada, contando com posto do PSF com médico que, embora distante $(3 \mathrm{~km})$, ainda era mais perto do que o posto da localidade de $\mathrm{X}$ (6 km), além da presença mais permanente do médico, ao contrário da outra, que referiu alta rotatividade e ausência frequente desse profissional. Não foi identificada nessas localidades presença de questões que a literatura tem asso- 
ciado a baixo nível de controle social, a saber: cooptação de lideranças pelo governo, distanciamento da representação de suas bases sociais (Labra e Figueiredo, 2002). Ao contrário, eram organizações com participação intensa dos associados com assembleias frequentes para discutir problemas da vida coletiva, experiências de coletivização da produção rural, construção de uma ponte em regime de mutirão de trabalho em 2006 e com material reivindicado das prefeituras e organização autônoma de escola de alfabetização, além da própria luta anterior pela posse da terra.

Chamou a atenção, nas respostas abertas sobre condição de atendimento à saúde, a referência frequente a pagamento de procedimentos, o que foi confirmado durante dois grupos focais realizados com cerca de 50 moradores adultos das duas localidades. Em X as cobranças se davam especialmente para os exames complementares (patologia clínica, raio X) e eram realizadas pelo prestador hospitalar filantrópico. Em Y o processo era um pouco distinto, pois o hospital público não cobrava por atendimentos, porém para aqueles exames onde era necessário recorrer à rede de saúde fora do município havia uma cobrança de procedimentos e de transporte por parte do município. Havia uma resignação indignada, e causou surpresa a indagação feita pelos pesquisadores acerca da necessidade de investigar a legalidade do procedimento.

A observação participante ocorreu em audiência da entidade representativa dos pequenos proprietários rurais da localidade de X com o secretário municipal de Saúde, com a presença total de oito pessoas e duração de sessenta minutos. Essa audiência foi filmada pela entidade. Vários temas foram discutidos: o problema da ausência do médico no posto do PSF, a marcação de consultas no hospital, os atendimentos de emergência, o desempenho do agente comunitário de saúde. Quando o tema da cobrança de exames foi levantado, o secretário prestou os seguintes esclarecimentos: a) que o hospital, embora seja fundação com a participação de muitas entidades de cunho comunitário no seu conselho (Rotary Clube, igrejas), com todos os leitos e serviços credenciados pelo SUS, possuía autonomia administrativa e financeira para a cobrança de procedimentos; b) que ele tinha uma cota mensal de exames pagos pela prefeitura ao hospital constante na sua programação pactuada e integrada; c) para administrar a demanda de exames vis-à-vis a cota estabelecida, ele fazia uma seleção com critérios socioeconômicos, em que estabelecia um percentual de 
participação do usuário que variava de 0 a $100 \%$ do preço do procedimento; d) ao ser confrontado com a ilegalidade do procedimento, em última análise, caso a pessoa não quisesse pagar, ele alegou autorizar o procedimento. Algumas condições eram isentas de coparticipação, como estado de gestação, o que foi contestado pelos moradores. Tema que mobilizou uma boa parte da audiência referiu-se às condições do hospital sem fins lucrativos e a ameaça de fechamento por conta de dívidas e financiamento público considerado insuficiente.

As categorias temáticas extraídas dos discursos dos moradores, lideranças e do secretário estão contidas no Quadro 1:

\section{QUADRO 1}

Análise de discurso - localidades de municípios X e Y, estado de Minas Gerais, julho de 2009

\begin{tabular}{|l|l|l|}
\hline \multicolumn{1}{|c|}{ Moradores } & \multicolumn{1}{|c|}{ Lideranças } & Secretário Municipal de Saúde \\
\hline $\begin{array}{l}\text { Cobrança é procedimento } \\
\text { comum. }\end{array}$ & $\begin{array}{l}\text { Hospital necessitaria ser publici- } \\
\text { zado - ter controle do município } \\
\text { e da população. }\end{array}$ & $\begin{array}{l}\text { Os municípios eram penalizados } \\
\text { pelo financiamento do SUS. }\end{array}$ \\
\hline $\begin{array}{l}\text { Cobrança associada à rapidez } \\
\text { na realização dos exames. }\end{array}$ & $\begin{array}{l}\text { Cobrança representava uma sobre- } \\
\text { carga em famílias que não tinham } \\
\text { renda suficiente. }\end{array}$ & $\begin{array}{l}\text { Pequenos hospitais não eram prio- } \\
\text { ridade do SUS. }\end{array}$ \\
\hline $\begin{array}{l}\text { Receios quanto a represálias indi- } \\
\text { viduais no atendimento à saúde por } \\
\text { parte da Secretaria Municipal de } \\
\text { Saúde em face do movimento. }\end{array}$ & $\begin{array}{l}\text { Seleção dos gratuitos e pagantes } \\
\text { era justa. }\end{array}$ \\
\hline
\end{tabular}

Fontes: Entrevistas, grupos focais e observação participante

\section{Discussão}

Percebe-se a ausência de sintonia entre a produção acadêmica brasileira e a realidade no caso das cobranças de usuários no SUS que levam a indagar sobre certo receio de abordagem dos problemas concretos da sua implementação, como se a exposição de mazelas significasse vulnerabilizar o modelo. 
O levantamento exploratório de documentos encontrados na internet sugere tratar-se de uma prática mais frequente em cidades de pequeno porte no interior do país, embora não específica destes, como no caso de Campos (RJ). A análise da PNAD sugere uma correspondência fraca entre isso, pois se por um lado mostra uma frequência maior da cobrança em estados da Região Norte, não demonstra nos demais uma diferença marcante entre regiões metropolitanas e interior. Deve-se ressaltar uma limitação dessa pesquisa, pois considera apenas o que foi identificado pela demanda como atendimento principal, o que pode não ser o caso dos exames complementares, que foram os itens, no estudo de caso, onde se dava a cobrança, e não em consultas e internações. Além disso, a PNAD não tem representatividade para o interior dos estados, e existe um hiato de seis anos entre os últimos dados acessíveis e a época do trabalho de campo.

De fato, para as populações do interior há uma ausência frequente de alternativas assistenciais entre diferentes prestadores públicos, o que possibilitaria ao usuário confrontar diversas práticas. Essa ausência poderia tornar o cidadão mais vulnerável a cobranças em face de uma necessidade de saúde, especialmente de urgência, tendo que contar com a boa vontade do único prestador de saúde disponível. Isso ficou claro nas preocupações das lideranças no estudo de caso. A análise realizada por Espindola (2004) das cartas com denúncia de usuários do SUS corrobora essa hipótese:

A maior parte dos usuários deseja manter em segredo a sua denúncia, pois teme sofrer represálias por parte do hospital, de não receber assistência médica quando necessitar de novo, ainda mais se considerar que em vários municípios existe um único hospital que atende pelo SUS. Das cartas objeto deste estudo, $62 \%$ dos usuários solicitaram sigilo da denúncia, destas $87,5 \%$ estavam relacionados à cobrança pelo atendimento. O sentimento de temor pela represália algumas vezes pode ter fundamento, pois fatos inusitados ocorreram quando do levantamento realizado pelo Denasus [...]. Um desses fatos chegou a conhecimento do DENASUS via denúncia anônima por telefone, ficou conhecido como kit cartas. Consistia na oferta de um kit de medicamento mais $\mathrm{R} \$ 75,00$ pelo fornecimento da carta para que não fosse respondida. Outro caso foi de um prefeito do interior, dono do único hospital de cidade, cujo parente era responsável pelo correio, dessa forma todas as cartas iam parar na casa do prefeito. (p. 44-45) 
Isso também explicaria a resignação encontrada na pesquisa e a ausência de posicionamento dos órgãos de controle social da saúde sobre o fato. Vianna, Piola e Ocké-Reis (1998, p. 24) diriam ainda na década de 1990: "cobrança indevida, conhecida como pagamento por fora, prática que prospera [...] sem provocar a mobilização indignada das representações dos usuários nos Conselhos de Saúde". Melo (2005) identifica até uma resolução do Conselho Municipal de Saúde de Campos (RJ) de 1996 legitimando a prática.

Ao contrário da maior parte dos trabalhos compilados (Vianna, Piola e Ocké-Reis, 1998; Melo, 2007; Espindola, 2004 e Melo, 2005) onde o prestador efetuou a cobrança indevida, o caso foi o único onde o próprio município efetua essa cobrança. Como, exploratoriamente, foi encontrado na auditoria do SUS ${ }^{2}$ caso semelhante de prefeitura que fazia, também em Minas Gerais, em 2004, cobrança por meio de consórcio de municípios, de valores aos usuários para obter atendimento em especialidades médicas não existentes na rede municipal, um desdobramento desse trabalho envolveria análises específicas dessa fonte.

Argumentos por parte de prestadores e municípios de subfinanciamento do SUS justificando a prática também são encontrados em Vianna, Piola e OckéReis (1998) e Melo (2005).

A rapidez de atendimento coincide com o trabalho de Melo (2005) como instrumento potente da anuência dos usuários em pagar pelos procedimentos.

As características da população pagante em Campos (Melo, 2005) em relação à não pagante diferem principalmente na renda média familiar. Entretanto, os valores refletem que o gasto adicional não recai sobre segmentos prósperos: 0,8 salário-mínimo (SM) contra 1,2 para os pagantes. Em nossa observação direta dos domicílios, também nos pareceu que a população que referia pagamentos apresentava uma condição de vida com baixa capacidade de consumo de bens e serviços monetarizados.

Destaca-se, ainda, a pertinência de ressaltar outro aspecto. Embora não tenha ficado evidente o mecanismo pelo qual se dava a cobrança no município Y, claramente, em X, era viabilizada pela existência de um modelo de gestão de fundação privada administrando o hospital, que na sua totalidade oferecia

2. Disponível em: $<$ http://sna.saude.gov.br/con_auditoria.cfm?aud=4185>. Acesso em: 26 ago. 2009. 
serviços ao SUS. No debate sobre o papel específico da transformação de um modelo de gestão de unidades públicas de saúde no sentido de maior flexibilidade gerencial, associado à privatização por meio de organizações sociais e fundações privadas, com alguma frequência, a literatura, polarizada, se centra na discussão sobre a modernização da gestão e a pretensa melhoria da eficiência versus o controle e a precarização do trabalho (Ibanez e Vecina Neto, 2007; Paim e Teixeira, 2007; Granemann, 2008). Entretanto, há outro aspecto que se refere aos impactos sobre os usuários dessas organizações quanto à facilitação da existência da dupla porta de entrada (Weichert, 2009) e, como no caso analisado, ao desenvolvimento de mecanismos de indução a pagamentos diretos por parte da demanda. A despeito de as iniciativas governamentais recentes procurarem se desvencilhar de uma associação com práticas privadas por parte desses novos entes jurídicos em curso no país (Machado, 2007), é necessário considerar que no projeto inicial das organizações sociais (Brasil, Maré, 1997) se supunha a necessidade de a instituição ter um plano de negócios, identificando as diversas possibilidades de financiamento privadas, antes da definição dos recursos públicos a serem alocados, considerados complementares (Andreazzi, 1997). Cabe lembrar que recentemente foi aprovado o Projeto de Lei estadual n. 62/2008, que permite que as organizações sociais em São Paulo que gerem hospitais possam dedicar até $25 \%$ dos atendimentos a pacientes pagantes (diretos ou via planos privados de saúde) (Fiori, 1992).

\section{Considerações finais}

As cobranças indevidas aos usuários do SUS trata-se de anomalias expostas apenas nas páginas dos auditores do SUS e do Ministério Público? Tratandose de estudo exploratório e com fontes pouco organizadas, sem dúvida seria importante, para responder essa pergunta, aprofundar o escopo de investigação, considerando essas fontes e inquéritos populacionais mais amplos.

Entretanto, é legítimo pensar se essas cobranças ilegais não apontam que a implementação efetiva da política de saúde no país a partir dos anos 1990, particularmente por meio da descentralização subfinanciada, demonstra o êxito parcial da agenda neoliberal em se materializar. 
Seus mecanismos potentes seriam a resignação naturalizada da população, especialmente nas cidades de menor porte, onde opções entre sistemas públicos inexistem. E também dos gestores de saúde municipais mais conscientes do caráter anticonstuticional do fato. Ainda que estes não tenham se rendido ideologicamente ao projeto, o justificam como mal menor diante da insuficiência de recursos. Quando não, aproveitam-se das necessidades prementes da população para perpetuar e renovar práticas coronelistas, tais como a concessão de acesso à atenção pública gratuita, que se constitui num direito, pelo domínio patrimonial do Estado. E sua via de implementação, por prestadores preferencialmente paraestatais e filantrópicos, utilizando os mecanismos de dupla porta de entrada para agilizar atendimentos.

Poderia tal (des)caminho ser atribuído a um desvio de implementação? Interessante síntese nesse sentido pode ser vista em Paim e Teixeira (2007, p. 1820):

Enquanto processo, a Reforma Sanitária enfrentou-se com obstáculos consideráveis nos últimos vinte anos, apesar das conquistas indiscutíveis. Além da insuficiência e instabilidade do financiamento público para o SUS, persistem problemas de gestão, especialmente no que diz respeito aos estabelecimentos de saúde, como hospitais e serviços de atenção básica. A falta de profissionalização de gestores, a descontinuidade administrativa, o clientelismo político e a interferência político-partidária no funcionamento dos serviços comprometem a reputação do SUS perante os cidadãos e a expectativa dos servidores públicos enquanto trabalhadores e partícipes de um projeto civilizatório do escopo da Reforma Sanitária Brasileira.

Ou há outra possibilidade insuficientemente avaliada pelo desenho da reforma do setor de saúde brasileiro dos anos 1980 que, ao conter pontos assemelhados com a agenda neoliberal, como a descentralização, não apresentou de forma clara os condicionantes de seu desenvolvimento num caminho democrático. Um deles é o caráter do Estado historicamente constituído no Brasil. Não desconhecendo a polêmica em torno das características do capitalismo que se instala no país, é permitido reivindicar suas ligações com o capital internacional (Lessa e Dain, 1982) e com a tradicional classe latifundiária, e a utilização maciça do aparelho do Estado como alavancagem da acumulação (Fiori, 1992), a resultante concentração da terra e da riqueza (Pochmann, 2004). Para- 
fraseando ainda Paim e Teixeira (2007, p. 1821): "um Estado, como o brasileiro, é patrimonialista, autoritário, burocrático e colonizado por interesses privados". A influência que essa concentração econômica precoce e persistente na nossa história exerce sobre o Estado é grande, dando-lhe um caráter pouco permeável à implementação de políticas democratizantes, como é o caso do SUS. Respostas que foram dadas pelos documentos da época quanto ao controle social no nível local subestimaram a capacidade dos grupos de poder de manipular o processo e cooptar lideranças dos usuários (Nogueira e Mioto, 2006), bem como de dificultar a participação de conselheiros provindos das camadas populares (Franco-Giraldo, Palma e Alvarez Dardet, 2006).

Respostas atuais no campo da desestização com publicização (reforma do Estado através de organizações sociais, organizações da sociedade civil de interesse público e fundações de direito privado) aparentemente ignorariam que as relações sociais consubstanciadas nos estados também permeiam a sociedade civil. A impossibilidade de vislumbrar caminhos mais eficazes e rupturas necessárias para a efetivação da reforma democrática da saúde poderia refletir uma concepção idealista do Estado e, portanto, que não leva em conta a história das formações sociais capitalistas?

Procuramos neste artigo chamar a atenção para um fenômeno pouco visível academicamente, que é a consolidação do modelo neoliberal na saúde, exemplificado na descentralização com aumento da participação do cidadão no financiamento da atenção à saúde por meio das cobranças ilegais, que podem se legalizar pelo modelo da terceirização da gestão das unidades públicas. Dois fatores se fazem presentes nessa via de institucionalizar a cobrança: a dupla porta de entrada com limitação objetiva da oferta pública e a naturalização resignada da população, em especial aquela mais diretamente dependente do prestador local. O mesmo modelo internacional de reformas que ocorreu amplamente na América Latina (Franco-Giraldo, Palma e Alvarez Dardet, 2006), o qual afirmamos não termos seguido pela porta da frente (a Constituição de 1988) (Fleury, 1995), entra pelos fundos e se consolida ideológica e independentemente da coloração política do governante da vez. Fenômeno esse que necessita de um melhor mapeamento de sua magnitude e extensão, bem como monitoramento de seu porvir, pois, aparentemente casual, sua mera existência reflete a contradição básica do SUS: concepção welfariana dentro do modelo econômico neoliberal e de Estado burocrático-patrimonial. Tendo como pano 
de fundo de sua consolidação os projetos do Banco Mundial e outros organismos internacionais, é necessário colocá-lo na agenda de preocupações quanto aos cenários de desenvolvimento do SUS, em se mantendo os atuais marcos de subfinanciamento, estímulo à terceirização da gestão e a ampliação do financiamento privado da saúde no país.

Artigo recebido em nov./2010 - Aprovado em dez./2010

\section{Referências bibliográficas}

ALMEIDA, C. Equidade e reforma setorial na América Latina: um debate necessário. Cad. Saúde Pública [on-line], v.18, 2002 suppl. [cited 2010-02-14], p. S23-S36. Disponível em: $<\mathrm{http}: / \mathrm{www}$.scielo.br/scielo.php?script=sci_arttext\&pid=S0102-311X20 02000700004\&lng=en\&nrm=iso $>$. ISSN 0102-311X. doi: 10.1590/S0102311X2002000700004. Acesso em: 24 ago. 2009.

ANDREAZZI, M. F. S. Privatização de leitos em hospitais públicos no Brasil: debate atual, problemas e impactos. In: ANDREAZZI, M. F. S.; TURA, L. F. R. Financiamento e gestão do setor Saúde: novos modelos. Rio de Janeiro: Ed. Anna Néry, 1997. p. 105-132.

BANCO MUNDIAL Brasil: novo desafio à saúde do adulto. Washington, DC, 1991. . A organização, prestação e financiamento da Saúde no Brasil: uma agenda para os anos 90. Washington, DC, 1995 (Relatório n. 12655 - BR).

. El financiamiento de los servicios de salud en los países en desarrollo. Una agenda para La reforma. In: ORGANIZACIÓN PANAMERICANA DE LA SALUD ECONOMÍA DE LA SALUD. Perspectivas para América Latina. Publicación Científica. Washington, DC, n. 517, p. 145-167, 1989.

. Relatório sobre o desenvolvimento mundial de 1993: investindo em saúde. Rio de Janeiro: FGV, 1993.

BARDIN, L. Análise de conteúdo. Lisboa: Ed. 70, 1997.

BJORKMAN, J.W. Reformas de saúde em perspectiva comparada - uma questão sem fim .... ou uma busca improvável. Ciência \& Saúde Coletiva, v. 14, n. 3, p. 763-770, 2009. 
BRASIL, MINISTÉRIO DA ADMINISTRAÇÃO FEDERAL E REFORMA DO ESTADO - MARE. Plano diretor da reforma do Estado. Brasília: Ministério da Administração Federal e Reforma do Estado, 1995.

. Organizações sociais. Brasília: Ministério da Administração e Reforma do Estado, 1997.

BRASIL, MINISTÉRIO DA SAÚDE. Secretaria Executiva. Caderno de Informações de Saúde. Versão de fevereiro de 2009. Brasília, 2009. Disponível em: <http://tabnet. datasus.gov.br/tabdata/cadernos/mg.htm>. Acesso em: 24 ago. 2009.

- Departamento Nacional de Auditoria do SUS. Orientações técnicas sobre aplicação de glosas em auditoria no SUS. Brasília: Departamento Nacional de Auditoria do SUS, 2005.

CAMARGO, B. Assembleia aprova Projeto de Lei Complementar 62/2008. Portal da Assembleia Legislativa do Estado de São Paulo, 2/9/2009. Disponível em: < http://www. al.sp.gov.br/portal/site/Internet/menuitem.4b8fb127603fa4af58783210850041 ca/?vgn extoid=f6b3657e439f7110VgnVCM100000590014acRCRD\&id=19583dfeedc73210 VgnVCM100000600014ac>. Acesso em: 11 set. 2009.

ESPINDOLA, M. C. Estudo das denúncias feitas pelos usuários do SUS contra os prestadores de serviços de saúde por meio da carta ao usuário do SUS na Regional de Saúde de Campo Grande/MS. Monografia de conclusão de curso. Especialização em Equipes Gestoras de Serviços e Sistemas de Saúde, UFMS, Campo Grande, 2004.

FIORI, J. L. Para repensar o papel do Estado sem ser um neoliberal. Rev. Econ. Politi$c a$, v. 12, n. 1, p. 76-89, 1992.

FLEURY, Sonia. Iniquidades nas políticas de saúde: o caso da América Latina. Rev. Saúde Pública [on-line], v. 29, n. 3, p. 243-250, 1995. ISSN 0034-8910.

FRANCO-GIRALDO, A.; PALMA, M.; ÁLVAREZ-DARDET, C. Efecto del ajuste estructural sobre la situación de salud n América Latina y el Caribe, 1980-2000. Rev. Panam. Salud Publica. v. 19, n. 5, p. 291-299, 2006.

GRANEMANN, S. Fundações estatais: projeto de Estado do capital. Mimeo, 2008 Disponível em: $<$ http://dceufpr.files.wordpress.com/2008/08/fundacoes-sara-granemann. pdf>. Acesso em: 3 set. 2009.

IBANEZ, N.; VECINA NETO, G. Modelos de gestão e o SUS. Ciência \& Saúde Coletiva, 12(Sup.): 1831-1840, 2007.

KUMAR, K. (Ed.). Rapid appraisal methods. World Bank Regional and Sectoral Studies, 1993. 
LABRA, M. E.; FIGUEIREDO, J. S. A. Associativismo, participação e cultura cívica: o potencial dos Conselhos de Saúde. Ciência \& Saúde Coletiva, v. 7, n. 3, p. 537-547, 2002.

LESSA, C.; DAIN, S. Capitalismo associado: algumas referências para o tema Estado e desenvolvimento. In: BELLUZO, L.; COUTINHO, R. (Orgs.). Desenvolvimento capitalista no Brasil: ensaios sobre a crise. São Paulo: Brasiliense, 1982.

MACHADO, K. Um novo modelo de gestão em debate. Radis - Comunicação em Saúde Rio de Janeiro, n. 58, jun. 2007. Disponível em: <http://www4.ensp.fiocruz.br/ radis/58/02.html>. Acesso em: 4 set. 2009.

MELO, E. M. et al. A organização da atenção básica em municípios integrantes do Projeto de Expansão e Consolidação do Saúde da Família em Mato Grosso. Cad. Saúde Pública, Rio de Janeiro, n. 24, Sup. 1:S29-S41, 2008.

MELO, M. B. Sistema Nacional de Auditoria: estruturação, avanços e força de trabalho. Tese de Doutoramento. Escola Nacional de Saúde Pública, Rio de Janeiro, 2007.

MELO, M. V. M. Impactos da consulta social no acesso ao sistema de saúde no município de Campos dos Goytacazes-RJ. In: PIOLA, Sérgio Francisco; JORGE, Elias Antonio. Prêmio em economia da saúde: $1^{\circ}$ prêmio nacional, 2004: coletânea premiada. Brasília: Instituto de Pesquisa Econômica Aplicada, 2005. p. 324-365.

MOREIRA, M. R.; ESCOREL, S. Conselhos Municipais de Saúde do Brasil: um debate sobre a democratização da política de saúde nos vinte anos do SUS. Ciência \& Saúde Coletiva, v. 14, n. 3, p. 795-805, 2009.

NOGUEIRA, V. M. R.; MIOTO, R. C. T. Desafios atuais do Sistema Único de Saúde - SUS e as exigências para os assistentes sociais. In: MOTA, A. E.; BRAVO, M. I. Serviço Social e Saúde: formação e trabalho profissional. São Paulo: Ministério da Saúde, OPAS, OMS, 2006. p.1-25.

PAIM, J. S.; TEIXEIRA, C. F. Configuração institucional e gestão do Sistema Único de Saúde: problemas e desafios. Ciência \& Saúde Coletiva [on-line], v.12, suppl., p. 1819$-1829,2007$.

POCHMANN, M. Proteção social na periferia do capitalismo: considerações sobre o Brasil. São Paulo em Perspectiva. [on-line], v.18, n. 2, p. 3-16, 2004.

RIBEIRO, P. A. S. Estudo de caso: a avaliação de satisfação do usuário na área de saúde do governo federal. Trabalho apresentado no VII Congreso Internacional del CLAD sobre la Reforma del Estado y de la Administración Pública, Lisboa, Portugal, 8-11 out. 2002. Disponível em: <http://www.clad.org.ve/fulltext/0043722.pdf>. Acesso em: 24 ago. 2009. 
TRAVASOS, C.; MARTINS, M. Uma revisão sobre os conceitos de acesso e utilização de serviços de saúde. Cad. Saúde Pública [on-line], v. 20, 2004 suppl.2 [cited 2010-0214], p. S190-S198. Disponível em: <http://www.scielo.br/scielo.php?script=sci arttext\&pid=S0102-311X2004000800014\&lng=en\&nrm=iso $>$. ISSN 0102-311X. doi: 10.1590/S0102-311X2004000800014. Acesso em: 28 ago. 2009.

VIANNA, S. M.; PIOLA, S. F.; OCKÉ-REIS, C. O. Gratuidade no SUS: controvérsia em torno do co-pagamento. IPEA Texto para Discussão, Brasília, n. 587, 1998.

WEICHERT, M. A. Fundação estatal no serviço público de saúde: inconsistências e inconstitucionalidades. Rev. Direito Sanit. [on-line], v. 10, n. 1, p. 81-97, 2009. 